\title{
Interferon alpha-2a treatment for refractory Behcet uveitis in Korean patients
}

\author{
Ji Hwan Lee, Christopher Seungkyu Lee and Sung Chul Lee
}

\begin{abstract}
Background: To evaluate therapeutic outcomes of interferon alpha-2a (IFNa2a) treatment in patients with Behcet's disease who were refractory to immunosuppressive agents.

Methods: This retrospective case series reviewed the medical records of 5 patients with refractory Behcet uveitis from January 2011 to February 2017. IFNa2a was administered at a dose of 3 million IU 3 times per week. Clinical response, relapse rate, and change of visual acuity were evaluated.

Results: The mean age of patients was $39.60 \pm 9.21$ years, and the median treatment duration was 6 months. Four of the 5 patients (80\%) presented with responses to IFNa2a without any uveitis attack during the treatment period. The mean number of uveitis attacks/year per patient during the treatment was $0.40 \pm 0.89$. The mean log of the Minimum Angle of Resolution visual acuity improved from $1.44 \pm 0.38$ at baseline to $1.02 \pm 0.58$ at the final follow up.
\end{abstract}

Conclusions: IFNa2a is an effective therapy for Behcet uveitis refractory to conventional immunosuppressants in Korean patients.

Keywords: Behcet syndrome, Interferon-alpha, Therapeutics, Uveitis

\section{Background}

Behcet's disease (BD) is a chronic relapsing multisystem vasculitis mainly characterized by recurrent oral ulceration, genital ulceration, ocular lesions, and skin lesions [1]. Ocular involvement is one of the most serious complication of $\mathrm{BD}$, as repeated attacks of uveitis may result in blindness [2].

Corticosteroid treatment is the mainstay in the management of acute uveitic attacks, and immunosuppressive agents such as cyclosporine and azathioprine are usually effective in long-term management [3, 4]. Interferon alpha-2a (IFNo2a) has been reported to be effective and safe in refractory cases, although the optimal regimen has not yet been established [5-13]. In this study, we aimed to evaluate the efficacy of IFNa2a in Korean patients with Behcet uveitis refractory to immunosuppressive agents.

\footnotetext{
* Correspondence: sunglee@yuhs.ac

Department of Ophthalmology, The Institute of Vision Research, Yonsei University College of Medicine, Yonsei-ro 50-1, Seodaemun-gu, Seoul, Republic of Korea
}

(c) The Author(s). 2018 Open Access This article is distributed under the terms of the Creative Commons Attribution 4.0 International License (http://creativecommons.org/licenses/by/4.0/), which permits unrestricted use, distribution, and reproduction in any medium, provided you give appropriate credit to the original author(s) and the source, provide a link to the Creative Commons license, and indicate if changes were made. The Creative Commons Public Domain Dedication waiver (http://creativecommons.org/publicdomain/zero/1.0/) applies to the data made available in this article, unless otherwise stated.
IFN $2 \mathrm{a}$ (Roferon-Aं; Roche; Basel, Switzerland) was administered at a dose of $3 \times 10^{6}$ IU 3 times per week. All previous immunomodulatory agents were stopped

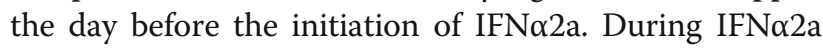
therapy, oral corticosteroid was tapered to a low dose $(5-10 \mathrm{mg} / \mathrm{d}$ prednisolone equivalent) or discontinued according to a general tapering schedule (to reduce by 
$5 \mathrm{mg} /$ day every 1-2 weeks if the dose of prednisolone is $20-40 \mathrm{mg} /$ day, to reduce by $2.5 \mathrm{mg} /$ day every $1-2$ weeks if the dose is below $20 \mathrm{mg}$ ).

\section{Assessments}

All patients underwent a complete ophthalmologic examination, including best-corrected visual acuity (BCVA), slit lamp biomicroscopy, tonometry, and fundoscopy. Ancillary examinations included fluorescein angiography and optical coherence tomography. Examinations were performed weekly for 2 weeks, every 2 weeks for 1 month, and then once every month. Relapse was defined as two step increase in level of inflammation including anterior chamber cells or vitreous haze [15]. The relapse rate was calculated as attacks per year. Response to IFN $\alpha 2 a$ therapy was defined as maintenance of inactive disease without any relapse during the treatment period. The mean LogMAR BCVA and the mean number of uveitis attacks per year at baseline and final visit were compared using Wilcoxon signed-rank test. Statistical analyses were performed using SPSS version 23.0 (IBM; Chicago, IL, USA) and a $p$-value $<0.05$ was considered statistically significant.

\section{Results}

\section{Patients}

Demographic and clinical characteristics of patients are summarized in Table 1. The mean age of patients was $36.60 \pm 9.21$ years and 5 patients were male in this study.
The mean overall follow up period including the treatment period was $58.80 \pm 33.48$ months. All patients were Korean. Four patients $(80 \%)$ presented bilateral involvement. Extraocular manifestations of BD included oral aphthous ulcers and skin lesions in all patients (100\%), genital ulcer in 1 patient (20\%), gastrointestinal involvement in 2 patients (40\%), central nervous system involvement in 1 patient (20\%), and epididymitis in 1 patient (20\%). Prior to IFNa2a therapy, 3 patients received combination therapy of azathioprine, cyclosporine, or methotrexate, and 2 patients were treated with mycophenolate mofetil.

\section{Interferon alpha-2a treatment}

The median duration of IFN $\alpha 2 \mathrm{a}$ treatment was 6 months (range 2-28 months). Four (80\%) of 5 patients showed responses to IFN 22 a without any uveitis attack during the treatment period (Fig. 1). The mean number of uveitis attacks per year during the treatment was $0.40 \pm$ 0.89 , which decreased from $2.16 \pm 1.08$ before IFN $\alpha 2 \mathrm{a}$ therapy $(p=0.043)$. Four responsive patients could not discontinue IFN 2 a therapy in this study. One patient (20\%) received posterior subtenon triamcinolone injection during the treatment period. In 1 unresponsive patient, IFN $\alpha 2$ a was switched to infliximab. Visual acuity improved at final visit compared with baseline in all patients. The mean log of the Minimum Angle of Resolution (logMAR) BCVA changed from $1.44 \pm 0.38$

Table 1 Demographic and clinical characteristics of patients with refractory Behcet uveitis

\begin{tabular}{|c|c|c|c|c|c|}
\hline & Patient 1 & Patient 2 & Patient 3 & Patient 4 & Patient 5 \\
\hline Age-range at onset (years) & $20-30$ & $40-50$ & $20-30$ & $30-40$ & $30-40$ \\
\hline Duration of IFNa2a treatment (months) & 6 & 5 & 28 & 12 & 2 \\
\hline Overall follow-up period (months) & 51 & 27 & 34 & 72 & 110 \\
\hline Laterality & Bilateral & Unilateral & Bilateral & Bilateral & Bilateral \\
\hline Anatomic classification of uveitis & Panuveitis & Panuveitis & Panuveitis & Panuveitis & Panuveitis \\
\hline Extraocular manifestations of BD & $\begin{array}{l}\text { Oral ulcer } \\
\text { CNS } \\
\text { involvement } \\
\text { Epididymitis } \\
\text { Arthritis } \\
\text { Skin lesion (EN) }\end{array}$ & $\begin{array}{l}\text { Oral ulcer } \\
\text { Genital ulcer } \\
\text { Skin lesion(EN) } \\
\text { Gl involvement }\end{array}$ & $\begin{array}{l}\text { Oral ulcer } \\
\text { Skin lesion (folliculitis) } \\
\text { Gl involvement }\end{array}$ & $\begin{array}{l}\text { Oral ulcer } \\
\text { Skin lesion (EN) }\end{array}$ & $\begin{array}{l}\text { Oral ulcer } \\
\text { Skin lesion(EN) }\end{array}$ \\
\hline Previous immunosuppressive treatment & $\begin{array}{l}\text { Azathioprine } \\
100 \mathrm{mg} / \mathrm{d} \\
\text { Methotrexate } 17.5 \mathrm{mg} \\
\text { weekly }\end{array}$ & $\begin{array}{l}\text { Cyclosporine } 200 \text { mg/d } \\
\text { Azathioprine } 100 \text { mg/d, } \\
\text { Methotrexate } 17.5 \mathrm{mg} \\
\text { weekly }\end{array}$ & $\begin{array}{l}\text { Cyclosporine } 200 \\
\text { mg/d, Azathioprine } \\
100 \text { mg/d }\end{array}$ & $\begin{array}{l}\text { Mycophenolate } \\
\text { mofetil } 2 \mathrm{~g} / \mathrm{d}\end{array}$ & $\begin{array}{l}\text { Mycophenolate } \\
\text { mofetil } 2 \mathrm{~g} / \mathrm{d}\end{array}$ \\
\hline $\begin{array}{l}\text { Dose of oral corticosteroid } \\
\text { (mg/d prednisolone equivalent), } \\
\text { preTx } \rightarrow \text { postTx }\end{array}$ & $40 \rightarrow 10$ & $15 \rightarrow 0$ & $20 \rightarrow 0$ & $40 \rightarrow 5$ & $15 \rightarrow 0$ \\
\hline $\begin{array}{l}\text { Relapse rate (number of uveitis } \\
\text { attacks/year), preTx } \rightarrow \text { postTx }\end{array}$ & $2.13 \rightarrow 2$ & $1.64 \rightarrow 0$ & $4.00 \rightarrow 0$ & $1.80 \rightarrow 0$ & $1.22 \rightarrow 0$ \\
\hline Response to IFNa2a & No & Yes & Yes & Yes & Yes \\
\hline Adverse events & $\begin{array}{l}\text { Flu-like } \mathrm{Sx} \\
\text { Depression }\end{array}$ & Flu-like Sx & Flu-like Sx & Flu-like Sx & Flu-like Sx \\
\hline
\end{tabular}




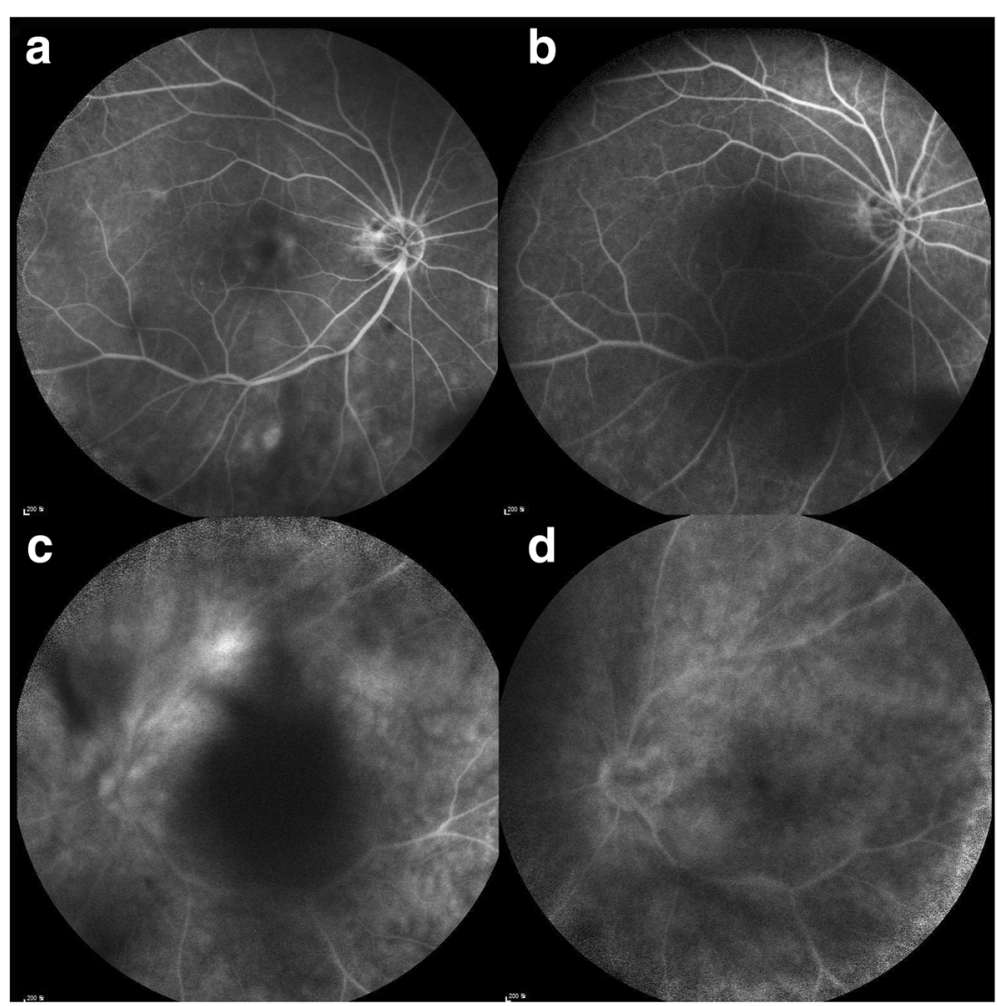

Fig. 1 Fluorescein angiographic images of patients with refractory Behcet uveitis. In patient 4, diffuse capillary leakage (a) decreased 6 months after interferon alpha-2a (IFNa2a) therapy (b). In patient 3, moderate vascluitis at the superior arcade (c) was significantly resolved 17 months after the initiation of IFNa2a treatment (d)

(Snellen equivalent 20/550) at baseline to $1.02 \pm 0.58$ (Snellen equivalent 20/209) at final visit $(p=0.068)$. Although the baseline BCVA was 20/200 or less in all patients (100\%), the final BCVA of $20 / 200$ or less were observed in 2 patients (40\%).

\section{Adverse events}

All patients experienced flu-like symptoms at the beginning of IFNa2a treatment. One patient presented with mild depression, which was relieved by antidepressant medication. No other significant adverse effects were observed during the treatment period.

\section{Discussion}

In this study, we evaluated the efficacy of IFN $\alpha 2 a$ in patients with Behcet uveitis refractory to immunosuppressive agents. Most patients had good responses to IFN $\alpha 2 \mathrm{a}$. IFN $\alpha 2 \mathrm{a}$ therapy was maintained in these patients. There were no uveitis attacks during the treatment period in the 4 patients who were responsive to IFN $\alpha 2 a$ therapy. Visual acuity improved in all patients.

Corticosteroid is the main treatment option for acute attacks of Behcet uveitis. However, its long-term use is limited because of adverse effects. Cyclosporine and azathioprine have been effectively used in Behcet uveitis alone or combined with other immunosuppressants in severe cases $[3,4]$. There are, however, some patients who are refractory to immunosuppressive agents, and biological therapies including anti-tumor necrosis factor antibody, anti-interleukin, or interferon can be considered in such cases $[16,17]$. Recently, IFN 2 2a has been reported to be effective for the treatment of refractory Behcet uveitis [5, 7-13, 18, 19].

There is no consensus on the dose and protocol of IFN $\alpha 2 a$ therapy for Behcet uveitis. In this study, we used a lower-dose regimen of $3 \times 10^{6}$ IU of IFN 2 2a 3 times per week during the treatment period. The rate of treatment response in our series was $80 \%$, which is similar to that in previous reports using higher doses of IFN 2 2a $[13,19]$. A lower-dose regimen may be associated with fewer treatment-related complications. There were no severe adverse effects in the present study. In contrast, patients with leukopenia or thrombocytopenia have been reported in previous studies using higher doses of IFN $\alpha 2 \mathrm{a}[18,20]$. Four responsive patients could not discontinue IFN $\alpha 2$ a therapy in this study, which may also have been associated with the lower dose of the regimen. By comparison, $25-50 \%$ of patients may discontinue IFN $\alpha 2$ a treatment with higherdose regimens $[11,13]$. 
The relapse rate of uveitis attacks significantly decreased from $2.16 \pm 1.08$ to $0.40 \pm 0.89$ after IFNo2a therapy. In the 4 patients who had responses to IFN $\alpha 2 \mathrm{a}$ therapy, there were no uveitis attacks during the treatment period. The efficacy of IFN $\alpha 2$ a therapy in terms of uveitis relapse was comparable to recent reports $[13,19]$. We confirmed that treatment response without uveitis relapse may be achieved mostly with low-dose continuous IFN 22 a therapy in Korean patients.

As refractory Behcet uveitis cases are rare, the major limitations of this study are its retrospective design and the small number of patients. We were, however, able to confirm the efficacy of IFNa2a therapy in a uniform low-dose regimen. Questions regarding the optimal dosage, treatment duration, and treatment protocol of IFN 2 2a therapy still remain unanswered. A prospective study would be necessary not only to determine the most effective and safest protocol, but also to compare the efficacy of IFN $2 \mathrm{a}$ with new biological agents currently under study.

\section{Conclusions}

IFN $\alpha 2 a$ is an effective therapeutic for Behcet uveitis refractory to other immunosuppressants in Korean patients.

\section{Abbreviations}

BCVA: best-corrected visual acuity; BD: Behcet's disease; IFNa2a: interferon alpha-2a; LogMAR: log of the minimum angle of resolution

\section{Acknowledgements \\ None.}

\section{Funding}

None.

\section{Availability of data and materials}

The datasets used and/or analyzed during the current study available from the corresponding author on reasonable request.

\section{Authors' contributions}

Conceptualization of the study JHL and SCL Data acquisition and analysis JHL, CSL and SCL Manuscript preparation JHL and CSL Analytic revision of manuscript SCL. All authors read and approved the final manuscript.

\section{Ethics approval and consent to participate}

This study was approved by the Institutional Review Board of Severance hospital (IRB No.4-2017-0436) and was conducted in accordance with the Declaration of Helsinki. Consent to participate from the patients was waived by the Institutional Review Board of Severance hospital (IRB No.4-2017-0436) as this was a retrospective chart review study.

\section{Consent for publication}

Not applicable.

\section{Competing interests}

The authors declare that they have no competing interests.
Received: 16 November 2017 Accepted: 14 February 2018

Published online: 20 February 2018

\section{References}

1. Sakane T, Takeno M, Suzuki N, Inaba G. Behcet's disease. N Engl J Med. 1999:341(17):1284-91.

2. Nussenblatt RB. Uveitis in Behcet's disease. Int Rev Immunol. 1997;14(1):67-79.

3. Masuda K, Nakajima A, Urayama A, Nakae K, Kogure M, Inaba G. Doublemasked trial of cyclosporin versus colchicine and long-term open study of cyclosporin in Behcet's disease. Lancet Lon Engl. 1989;1(8647):1093-6.

4. Yazici H, Pazarli H, Barnes CG, Tuzun Y, Ozyazgan Y, Silman A, Serdaroglu S, Oguz V, Yurdakul S, Lovatt GE, et al. A controlled trial of azathioprine in Behcet's syndrome. N Engl J Med. 1990;322(5):281-5.

5. Wechsler B, Bodaghi B, Huong DL, Fardeau C, Amoura Z, Cassoux N, Piette JC, LeHoang P. Efficacy of interferon alfa-2a in severe and refractory uveitis associated with Behcet's disease. Ocul Immunol Inflamm. 2000;8(4):293-301.

6. Kotter I, Zierhut M, Eckstein AK, Vonthein R, Ness T, Gunaydin I, Grimbacher B, Blaschke S, Meyer-Riemann W, Peter HH, et al. Human recombinant interferon alfa-2a for the treatment of Behcet's disease with sight threatening posterior or panuveitis. Br J Ophthalmol. 2003;87(4):423-31.

7. Krause L, Altenburg A, Pleyer U, Kohler AK, Zouboulis CC, Foerster MH. Longterm visual prognosis of patients with ocular Adamantiades-Behcet's disease treated with interferon-alpha-2a. J Rheumatol. 2008;35(5):896-903.

8. Deuter CM, Zierhut M, Mohle A, Vonthein R, Stobiger N, Kotter I. Long-term remission after cessation of interferon-alpha treatment in patients with severe uveitis due to Behcet's disease. Arthritis Rheum. 2010;62(9):2796-805.

9. Sobaci G, Erdem U, Durukan AH, Erdurman C, Bayer A, Koksal S, Karagul S, Bayraktar MZ. Safety and effectiveness of interferon alpha-2a in treatment of patients with Behcet's uveitis refractory to conventional treatments. Ophthalmology. 2010;117(7):1430-5.

10. Onal S, Kazokoglu H, Koc A, Akman M, Bavbek T, Direskeneli H, Yavuz S. Longterm efficacy and safety of low-dose and dose-escalating interferon alfa-2a therapy in refractory Behcet uveitis. Arch Ophthalmol. 2011;129(3):288-94.

11. Yalcindag FN, Uzun A. Results of interferon alpha-2a therapy in patients with Behcet's disease. J Ocul Pharmacol Ther. 2012;28(4):439-43.

12. Diwo E, Gueudry J, Saadoun D, Weschler B, LeHoang P, Bodaghi B. Longterm efficacy of interferon in severe uveitis associated with Behcet disease. Ocul Immunol Inflamm. 2017;25(1):76-84.

13. Hasanreisoglu M, Cubuk MO, Ozdek S, Gurelik G, Aktas Z, Hasanreisoglu B. Interferon alpha-2a therapy in patients with refractory Behçet uveitis. Ocul Immunol Inflamm. 2017;25(1):71-5.

14. International Study Group for Becet's Disease. Critertia for diagnosis of Behcet's disease. Lancet (London, England). 1990;335(8697):1078-80.

15. Jabs DA, Nussenblatt RB, Rosenbaum JT. Standardization of uveitis nomenclature for reporting clinical data. Results of the first international workshop. Am J Ophthalmol. 2005;140(3):509-16.

16. Calvo-Rio V, Blanco R, Beltran E, Sanchez-Burson J, Mesquida M, Adan A, Hernandez MV, Hernandez Garfella M, Valls Pascual E, Martinez-Costa L, et al. Anti-TNF-alpha therapy in patients with refractory uveitis due to Behcet's disease: a 1-year follow-up study of 124 patients. Rheumatology (Oxford). 2014;53(12):2223-31

17. Papo M, Bielefeld P, Vallet $H$, Seve P, Wechsler B, Cacoub P, Le Hoang P, Papo T, Bodaghi B, Saadoun D. Tocilizumab in severe and refractory noninfectious uveitis. Clin Exp Rheumatol. 2014;32(4 Suppl 84):S75-9.

18. Gueudry J, Wechsler B, Terrada C, Gendron G, Cassoux N, Fardeau C, Lehoang P, Piette JC, Bodaghi B. Long-term efficacy and safety of low-dose interferon alpha2a therapy in severe uveitis associated with Behcet disease. Am J Ophthalmol. 2008;146(6):837-44. e831

19. Park JY, Chung YR, Lee $K$, Song JH, Lee ES. Clinical experience of interferon alfa-2a treatment for refractory uveitis in Behcet's disease. Yonsei Med J. 2015:56(4):1158-62.

20. Tugal-Tutkun I, Guney-Tefekli E, Urgancioglu M. Results of interferon-alfa therapy in patients with Behcet uveitis. Graefes Arch Clin Exp Ophthalmol. 2006;244(12):1692-5.

\section{Publisher's Note}

Springer Nature remains neutral with regard to jurisdictional claims in published maps and institutional affiliations. 